\title{
Novel P2-type layered medium-entropy ceramics oxide as cathode material for sodium-ion batteries
}

\author{
Shengxue YAN ${ }^{a, b}$, Shaohua $\mathrm{LUO}^{a, b, c, d,{ }^{*}}$, Liu YANG ${ }^{a, b}, \mathrm{Jian}_{\mathrm{FENG}}{ }^{a, b}$, \\ Pengwei $\mathrm{LI}^{a, b}$, Qing WANG ${ }^{a, c}$, Yahui ZHANG ${ }^{a, b, c}$, Xin LIU ${ }^{a, b, c}$ \\ ${ }^{a}$ School of Materials Science and Engineering, Northeastern University, Shenyang 110819, China \\ ${ }^{b}$ Key Laboratory of Dielectric and Electrolyte Functional Material Hebei Province, School of Resources and \\ Materials, Northeastern University at Qinhuangdao, Qinhuangdao 066004, China \\ ${ }^{c}$ School of Resources and Materials, Northeastern University at Qinhuangdao, Qinhuangdao 066004, China \\ ${ }^{d}$ State Key Laboratory of Rolling and Automation, Northeastern University, Shenyang 110819, China
}

Received: April 15, 2021, Revised: July 30, 2021, Accepeted: August 25, 2021.

(C) The Author(s) 2021.

\begin{abstract}
High-entropy oxides (HEOs) and medium-entropy oxides (MEOs) are new types of single-phase solid solution materials. MEOs have rarely been reported as positive electrode material for sodium-ion batteries (SIBs). In this study, we first proposed the concept of the application of MEOs in SIBs. P2-type 3-cation oxide $\mathrm{Na}_{2 / 3} \mathrm{Ni}_{1 / 3} \mathrm{Mn}_{1 / 3} \mathrm{Fe}_{1 / 3} \mathrm{O}_{2}$ (NaNMF) and 4-cation oxide $\mathrm{Na}_{2 / 3} \mathrm{Ni}_{1 / 3} \mathrm{Mn}_{1 / 3} \mathrm{Fe}_{1 / 3-x} \mathrm{Al}_{x} \mathrm{O}_{2}$ (NaNMFA) were prepared using the solid-state method, rather than the doping technology. In addition, the importance of the concept of entropy stabilization in material performance and battery cycling was demonstrated by testing 3-cation (NaNMF) and 4-cation (NaNMFA) oxides in the same system. Thus, NaNMFA can provide a reversible capacity of about $125.6 \mathrm{mAh} \cdot \mathrm{g}^{-1}$ in the voltage range of $2-4.2 \mathrm{~V}$, and has enhanced cycle stability. The capacity and decay law of the MEO batteries indicate that the configurational entropy (1.28 R (NaNMFA) > 1.10 R (NaNMF)) of the cationic system, is the main factor affecting the structural and cycle stability of the electrode material. This work emphasizes that the rational design of MEOs with novel structures and different electrochemically active elements may be the strategy for exploring high-performance SIB cathode materials in next-generation energy storage devices.
\end{abstract}

Keywords: cathode materials; medium-entropy oxide (MEO); configuration entropy; electrochemical performance; sodium-ion batteries (SIBs)

\section{Introduction}

Recently, with the depletion of fossil fuels worldwide and the increasing energy demand, the development of humans in various fields, such as housing, industry,

\footnotetext{
* Corresponding author.

E-mail: tianyanglsh@163.com
}

military, aerospace, transportation, and other areas requires the development of storage systems and alternative energy conversion [1-4]. Sodium-ion batteries (SIBs) can complement lithium-ion batteries (LIBs), and can be used in electric vehicles and electrostatic storage because of their low cost $[5,6]$. Therefore, they have received attention in the energy storage industry. The cathode material is the key factor limiting the energy density of SIBs. 
Various positive electrode materials for SIBs, such as Prussian blue analogs, polyanionic compounds, and layered transition metal (TM) oxides have been investigated. The regulation effect on sodium ions in their crystal structure was studied [7-12]. P2-type $\mathrm{Na}_{2 / 3} \mathrm{Ni}_{1 / 3} \mathrm{Mn}_{2 / 3} \mathrm{O}_{2}$ $(\mathrm{NaNM})$ is characterized by its high voltage $(3.5 \mathrm{~V}$ vs. $\left.\mathrm{Na} / \mathrm{Na}^{+}\right)$. It has been studied because of its high theoretical $\left(173 \mathrm{mAh} \cdot \mathrm{g}^{-1}\right)$ and specific $\left(>140 \mathrm{mAh} \cdot \mathrm{g}^{-1}\right)$ capacities $[13,14]$. The first two features of NaNM are derived from the $\mathrm{O}^{2-} / \mathrm{O}^{2-n}$ reversible redox chemical reaction under high voltage and the multi-electron $\mathrm{Ni}^{2+} / \mathrm{Ni}^{4+}$ transfer center [15-17]. The third feature is that compared with the $\mathrm{Na}$ jump at the octahedral site of the $\mathrm{O}_{3}$ phase structure, the energy barrier of $\mathrm{Na}$ sliding at the triangular prism site of the P2 phase structure is lower [18].

P2-NaNM can provide excellent cycle stability at a cut-off voltage of $4.0 \mathrm{~V}[19,20]$. However, the capacity and voltage decay of P2-NaNM are fast when P2-NaNM is cycled at a high cut-off voltage of $4.4 \mathrm{~V}$. Such poor stability is due to the phase transition from $\mathrm{P} 2$ to $\mathrm{O} 2$ and the sliding of the $\mathrm{TMO}_{2}$ layer after $\mathrm{Na}$ extraction [21-24]. In addition, the two sequences in P2-NaNM, including $\mathrm{Na}^{+} /$vacancy sequence in $\mathrm{Na}$ layer and TM1/TM2 cation sequence in TM lattice, reduced $\mathrm{Na}$ diffusion and rate ability [25]. The introduction of inert metals ( $\mathrm{Al}, \mathrm{Mg}, \mathrm{Cu}, \mathrm{Zn}$, etc.) in the $\mathrm{TM}$ layer can alleviate problems associated with undesirable phase transition [26-29]. However, due to the $\mathrm{Na}^{+} /$vacancy order problem, the cycling capability and rate performance of P2-NaNM cannot be improved when cycling at a high cut-off voltage. Therefore, it is imperative to develop a solution to achieve a satisfactory balance among reversible capacity, structural stability, and $\mathrm{Na}$ diffusion.

In addition, cation doping is a favorable way to improve the electrochemical performance, such as electrolyte oxidative-decomposition prevention [30], TMS-dissolution inhibition [31], P2-O2 phase-transition inhibition [32], Jahn-Teller TM cation-distortion inhibition [33], metaloxygen bond enhancement [34], and surface basicity change [35]. Therefore, many researchers have studied the doping of different metals in P2-type SIB cathode materials, such as $\mathrm{Mg}$ [36], $\mathrm{Zr}$ [37], $\mathrm{Cu}$ [38], $\mathrm{CO}$ [39], $\mathrm{Ti}$ [40], and Al [41]. Doping is conducted through traditional synthesis methods, such as solid-state [42], sol-gel [43], and co-precipitation [44].

Compared with single metal oxides, high-entropy oxides (HEOs), as a new type of multi-component single-phase solid solution transition metal oxides (TMO), have higher electronic conductivity and various electrochemically active components $[45,46]$. HEOs involve introducing high configuration entropy to stabilize the single-phase structure. Another interesting discovery in Breitung's study is that $\mathrm{Na}_{y}\left(\mathrm{Co}_{0.2} \mathrm{Cu}_{0.2} \mathrm{Mg}_{0.2} \mathrm{Ni}_{0.2} \mathrm{Zn}_{0.2}\right) \mathrm{OCl}_{y}$ (designated as $\mathrm{Na}(\mathrm{HEO})-\mathrm{Cl})$ can also be prepared, which inspires the study of high-entropy cathodes for SIBs [47]. Such high-entropy compounds have been synthesized and reported, including carbides [48], diborides [49], nitrides [50], chalcogenides [51], and oxides [52], which are applied in thermoelectricity, dielectric, LIBs [53], and SIBs [54-59]. The groundbreaking work of Rost et al. [60] reported only the latter high-entropy material (HEM), in 2015, called entropy-stabilized oxides. They show a gradual lithium storage behavior, which reduces the volume change and solves the problem of induction electrode crushing to some extent. Therefore, HEOs have become an attractive research object. As the medium-entropy oxides (MEOs) [61,62], they have unlimited potential, and there is no report in this field yet.

Inspired by the preparation technology of MEOs, P2-type $\mathrm{Na}_{2 / 3} \mathrm{Ni}_{1 / 3} \mathrm{Mn}_{1 / 3} \mathrm{Fe}_{1 / 3} \mathrm{O}_{2} \quad$ (NaNMF) and $\mathrm{Na}_{2 / 3} \mathrm{Ni}_{1 / 3} \mathrm{Mn}_{1 / 3} \mathrm{Fe}_{1 / 3-x} \mathrm{Al}_{x} \mathrm{O}_{2}$ (NaNMFA) $(x=0,1 / 12$, and $1 / 6)$ were prepared using the solid-state method, instead of the doping technology. NaNMFA with high crystallinity, good orientation, and ideal particle/crystal size was obtained, and has high reversible capacity, good structural stability, and weak polarization. Through the phase analysis and electrochemical test, it is considered that the prepared NaNMFA cathode has a broad application prospect in high-performance SIBs.

\section{Experimental}

\section{1 Material preparation}

The P2-type medium-entropy oxides $\mathrm{Na}_{2 / 3} \mathrm{Ni}_{1 / 3} \mathrm{Mn}_{1 / 3} \mathrm{Fe}_{1 / 3} \mathrm{O}_{2}$ (NaNMF) and $\mathrm{Na}_{2 / 3} \mathrm{Ni}_{1 / 3} \mathrm{Mn}_{1 / 3} \mathrm{Fe}_{1 / 3-x} \mathrm{Al}_{x} \mathrm{O}_{2}$ (NaNMFA) $(x=0,1 / 12$, and $1 / 6)$ were synthesized using a conventional solid-state method. For $\mathrm{Na}_{2 / 3} \mathrm{Ni}_{1 / 3} \mathrm{Mn}_{2 / 3} \mathrm{O}_{2}$ (NaNM), $\mathrm{Na}_{2} \mathrm{CO}_{3}, \mathrm{NiO}, \mathrm{Fe}_{2} \mathrm{O}_{3}$, and $\mathrm{MnO}_{2}$ with stoichiometric amounts were ball milled for $4 \mathrm{~h}$ with absolute ethanol as the dispersant, dried at $80{ }^{\circ} \mathrm{C}$ for $12 \mathrm{~h}$, and pressed into a pellet under a pressure of $14 \mathrm{MPa}$. P2-type compounds were obtained by calcining at 700,800 , and $900{ }^{\circ} \mathrm{C}$ for 4,8 , and $12 \mathrm{~h}$ in air and then cooled to room temperature. At the same time, the reaction temperature was optimized to 900,950 , and $1000{ }^{\circ} \mathrm{C}$, and the corresponding samples were NaNMF-900, NaNMF-950, 
and NaNMF-1000, respectively. For NaNMFA samples, $\mathrm{Na}_{2} \mathrm{CO}_{3}$ (3.5\% excess, optimized excess was determined by orthogonal experiments and a single factor test) and $\mathrm{Al}_{2} \mathrm{O}_{3}$ were mixed, followed by the same preparation process with the calcination temperature $\left(950{ }^{\circ} \mathrm{C}\right)$ and calcination time $(12 \mathrm{~h})$ determined by orthogonal experiments. The obtained samples with $x=0, x=1 / 12$, and $x=1 / 6$ were prepared and denoted as NaNMFA-1, NaNMFA-2, and NaNMFA-3, respectively.

\section{2 Material characterization}

By X-ray diffraction (XRD; Rigaku, Japan) analysis using $\mathrm{Cu} \mathrm{K \alpha}$ rays $(\lambda=1.5406 \AA)$, the data were collected at $2 \theta=10^{\circ}-90^{\circ}$ at $4\left(^{\circ}\right) / \mathrm{min}$. The morphology and composition of the precursor and cathode powder were determined using a scanning electron microscope (SEM; Zeiss Supra 55, Germany). The structure of the material was characterized by transmission electron microscopy (TEM; JEM 2100F, Japan). X-ray photoelectron spectroscopy (XPS; Thermo Scientific K-Alpha, USA) was used to determine the valence state of the element.

\section{3 Electrochemical measurements}

Electrochemical tests were carried out in CR2032 coin type batteries, which were assembled in glove boxes filled with Ar. The prepared materials served as cathode, glass fiber as separator, and sodium ( $>99 \%$; Aldrich, USA) as anode. The positive electrodes were fabricated with a mixture of the synthesized oxide powder ( $80 \mathrm{wt} \%$ ), acetylene black (10 wt\%), and polyvinylidene fluoride (PVDF, $10 \mathrm{wt} \%$ ) in N-methyl-2-pyrrolidone (NMP). The slurry was coated on aluminum foil, and the electrode was cut into discs with an area of $0.785 \mathrm{~cm}^{2}$ and dried in a vacuum oven at $120{ }^{\circ} \mathrm{C}$. The loading of active material on each disc was about $1.5 \mathrm{mg}$. Charge/discharge performance was evaluated by Land CT2001A battery testing system in a voltage range of 2.0-4.2 and 4.2-2.0 V, respectively. The electrochemical impedance spectroscopy (EIS; Solartron 1260+1287 Electrochemical Workstation, UK) and cyclic voltammetry were collected on a Solartron $1260+1287$ electrochemical workstation in the same voltage range corresponded to the charge/discharge testing at a scan rate of $0.1 \mathrm{mV} \cdot \mathrm{s}^{-1}$.

\section{4 Configurational entropy in the ideal model}

The configuration entropy ( $\left.\Delta S_{\text {config }}\right)$ of the transition from $\Omega_{1}$ to $\Omega_{2}$ can be calculated according to the Boltzmann formula [63-66]:

$$
\Delta S_{\text {config }}=k \ln \Omega_{2}-k \ln \Omega_{1}
$$

where $k$ is the Boltzmann constant and $\Omega$ is the total number of all microstructures in a specific macroscopic state. For convenience, the configurational entropy per mole in an alloy system is approximately:

$$
\Delta S_{\text {config }}=-R \sum_{i=1}^{n} c_{i} \ln c_{i}=-R \sum_{i=1}^{n} \frac{1}{n} \ln \frac{1}{n}=R \ln n
$$

where $n$ is the number of elements, $c_{i}$ is the concentration of component $i$, and $R$ is the gas constant. When all the components are in an equal molar ratio, the configuration entropy reaches its maximum.

According to Eq. (2), the entropy values of the prepared oxides are $1.10 \mathrm{R}$ (NaNMF) and $1.28 \mathrm{R}$ (NaNMFA). According to previous reports, alloy systems are divided into three categories [67]: The first category is high-entropy alloys, which generally contain five or more components, and their mixed entropy is greater than or equal to $1.5 \mathrm{R}$; the second is medium-entropy alloys, which contain four main components, and the mixing entropy is between 1.0 and $1.5 \mathrm{R}$; the third low-entropy alloy is a traditional alloy based on one main component, and the mixing enthalpy is less than $1.0 \mathrm{R}$. Therefore, calculations show that the target product prepared is a medium-entropy oxide.

\section{Results and discussion}

\section{1 Effects of the preparation parameters on NaNMF}

Orthogonal experimental design is an economical and time-saving technology for process parameter optimization. In this study, the three factors, reaction temperature, heating rate, and soaking time were selected to analyze their influence on the performance of $\mathrm{Na}_{2 / 3} \mathrm{Ni}_{1 / 3} \mathrm{Mn}_{1 / 3} \mathrm{Fe}_{1 / 3} \mathrm{O}_{2}$ in the battery. Table 1 lists the specific parameters of each experiment, and the results are shown in Fig. 1. For the temperature factor, the specific capacity increases as the temperature rises. From 700 to $800{ }^{\circ} \mathrm{C}$, the specific capacity does not change significantly with increasing temperature, but when the temperature rises to $900{ }^{\circ} \mathrm{C}$, the specific capacity of the discharge changes greatly. Compared with the specific capacity of $800{ }^{\circ} \mathrm{C}$, there is a significant increase, so the optimal calcination temperature of orthogonal experiment is $900{ }^{\circ} \mathrm{C}$. As for the heating rate, as it increases, the change in discharge specific capacity first increases and then decreases. The discharge specific capacity is the highest when the heating rate is $4{ }^{\circ} \mathrm{C} \cdot \mathrm{min}^{-1}$. According to Table 2, the 
Table 1 Orthogonal experimental factors and levels

\begin{tabular}{cccc}
\hline Level & Temperature $\left({ }^{\circ} \mathrm{C}\right)$ & Heating rate $\left({ }^{\circ} \mathrm{C} \cdot \mathrm{min}^{-1}\right)$ & Soaking time $(\mathrm{h})$ \\
\hline 1 & 700 & 3 & 4 \\
2 & 800 & 4 & 8 \\
3 & 900 & 5 & 12 \\
\hline
\end{tabular}

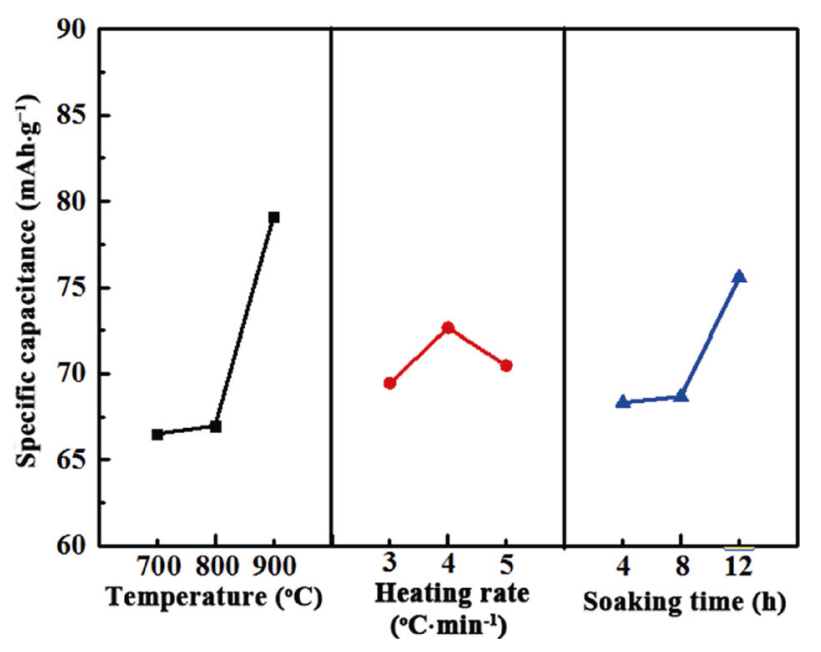

Fig. 1 Variation trends of the $\mathrm{Na}_{2 / 3} \mathrm{Ni}_{1 / 3} \mathrm{Mn}_{1 / 3} \mathrm{Fe}_{1 / 3} \mathrm{O}_{2}$ initial discharge capacity under different factors and levels.

Table 2 Orthogonal experimental design

\begin{tabular}{ccccc}
\hline Level & $\begin{array}{c}\text { Temperature } \\
\left({ }^{\circ} \mathrm{C}\right)\end{array}$ & $\begin{array}{c}\text { Heating rate } \\
\left({ }^{\circ} \mathrm{C} \cdot \mathrm{min}^{-1}\right)\end{array}$ & $\begin{array}{c}\text { Soaking time } \\
(\mathrm{h})\end{array}$ & $\begin{array}{c}\text { Specific capacity } \\
\left(\mathrm{mAh} \cdot \mathrm{g}^{-1}\right)\end{array}$ \\
\hline 1 & 700 & 5 & 4 & 73.6 \\
2 & 700 & 3 & 8 & 79.6 \\
3 & 700 & 4 & 12 & 84.1 \\
4 & 800 & 5 & 12 & 77.1 \\
5 & 800 & 3 & 4 & 60.1 \\
6 & 800 & 4 & 8 & 63.8 \\
7 & 900 & 5 & 8 & 60.8 \\
8 & 900 & 3 & 12 & 68.7 \\
9 & 900 & 4 & 4 & 70.1 \\
\hline $\mathrm{K} 1^{a}$ & 79.100 & 70.467 & 68.667 & 67.933 \\
$\mathrm{~K}^{b}$ & 66.967 & 69.450 & 75.583 & 68.033 \\
$\mathrm{~K}^{c}{ }^{c}$ & 66.500 & 72.650 & 68.317 & 76.600 \\
$R^{d}$ & 12.600 & 3.200 & 7.266 & 8.667 \\
\hline
\end{tabular}

${ }^{a}$ The corresponding mean value of the specific capacity at different temperatures.

${ }^{b}$ The corresponding mean value of the specific capacity at different heating rate.

${ }^{c}$ The corresponding mean value of the specific capacity at different calcination time.

${ }^{d}$ The extreme difference, which can reflect the importance of the effective factor.

range of heating rate is only 3.2 , indicating that the influence of heating rate on discharge capacity is very small and can be ignored. Therefore, the optimal heating rate is $5{ }^{\circ} \mathrm{C} \cdot \mathrm{min}^{-1}$ based on the principle of improving efficiency. The trend chart of the soaking time is similar to that of the calcination temperature. With the increase of the soaking time, the discharge capacity of the first cycle also increases. It can be seen from the trend chart that when the soaking time is $12 \mathrm{~h}$, the discharge capacity has a relatively large increase, so the best soaking time is $12 \mathrm{~h}$. The experimental results show that reaction temperature is the most important factor, followed by reaction time and soaking rate. Therefore, subsequent research focused on the effect of reaction temperature, while those of the calcination time and heating rate were not further investigated. Apparently, the synthetic condition of $\mathrm{Na}_{2 / 3} \mathrm{Ni}_{1 / 3} \mathrm{Mn}_{1 / 3} \mathrm{Fe}_{1 / 3} \mathrm{O}_{2}$ was as follows: heating rate $5{ }^{\circ} \mathrm{C} \cdot \mathrm{min}^{-1}$ and soaking time $12 \mathrm{~h}$.

\section{2 Reaction temperature optimization}

To optimize the experimental conditions, the calcination temperature is discussed. According to the orthogonal test design, calcination temperature is the main factor affecting the calcination effect. The samples were synthesized at a $5{ }^{\circ} \mathrm{C} \cdot \mathrm{min}^{-1}$ heating rate, and the soaking time was $12 \mathrm{~h}$.

Figure 2 shows the XRD patterns and corresponding Rietveld refinement of the NaNMF-900, NaNMF-950, and NaNMF-1000 samples calcined at different temperatures, and the corresponding crystallographic parameters from the Rietveld refinement are summarized in Table S1 in the Electronic Supplementary Material (ESM). When the NaNMF was calcined at 900, 950, and $1000{ }^{\circ} \mathrm{C}$, the diffraction peaks at $2 \theta$ appearing at $15.7^{\circ}, 31.9^{\circ}, 36.2^{\circ}, 39.7^{\circ}, 43.8^{\circ}, 49.1^{\circ}, 62.1^{\circ}, 65.3^{\circ}$, and $67.8^{\circ}$ could be assigned to the (002), (101), (100), (102), (103), (104), (006), (110), and (112) diffraction planes of a P2-type phase with a space group of $P 63 / m m c$, respectively, suggesting the formation of a pure-phase P2-type structure. The structural refinement studies performed on the powder diffraction pattern of P2-NaNMF-950 confirm hexagonal $P 63 / \mathrm{mmc}$ space group with lattice parameter of $a=2.894 \AA$ and $c=$ $11.216 \AA$.

To study the effect of Fe on material properties, the oxidation state information of NaNMF-950 was studied using XPS (Fig. 3). The binding energy of the sample was calibrated by introducing the $\mathrm{C} 1 \mathrm{~s}$ peak at $284.85 \mathrm{eV}$. The measurement spectrum of the sample shows peaks of C 1s, O 1s, Mn 2p, Fe 2p, and Na 1s (Fig. 3(a)). As shown in Fig. 3(b), the observed Fe 2p peaks located at 

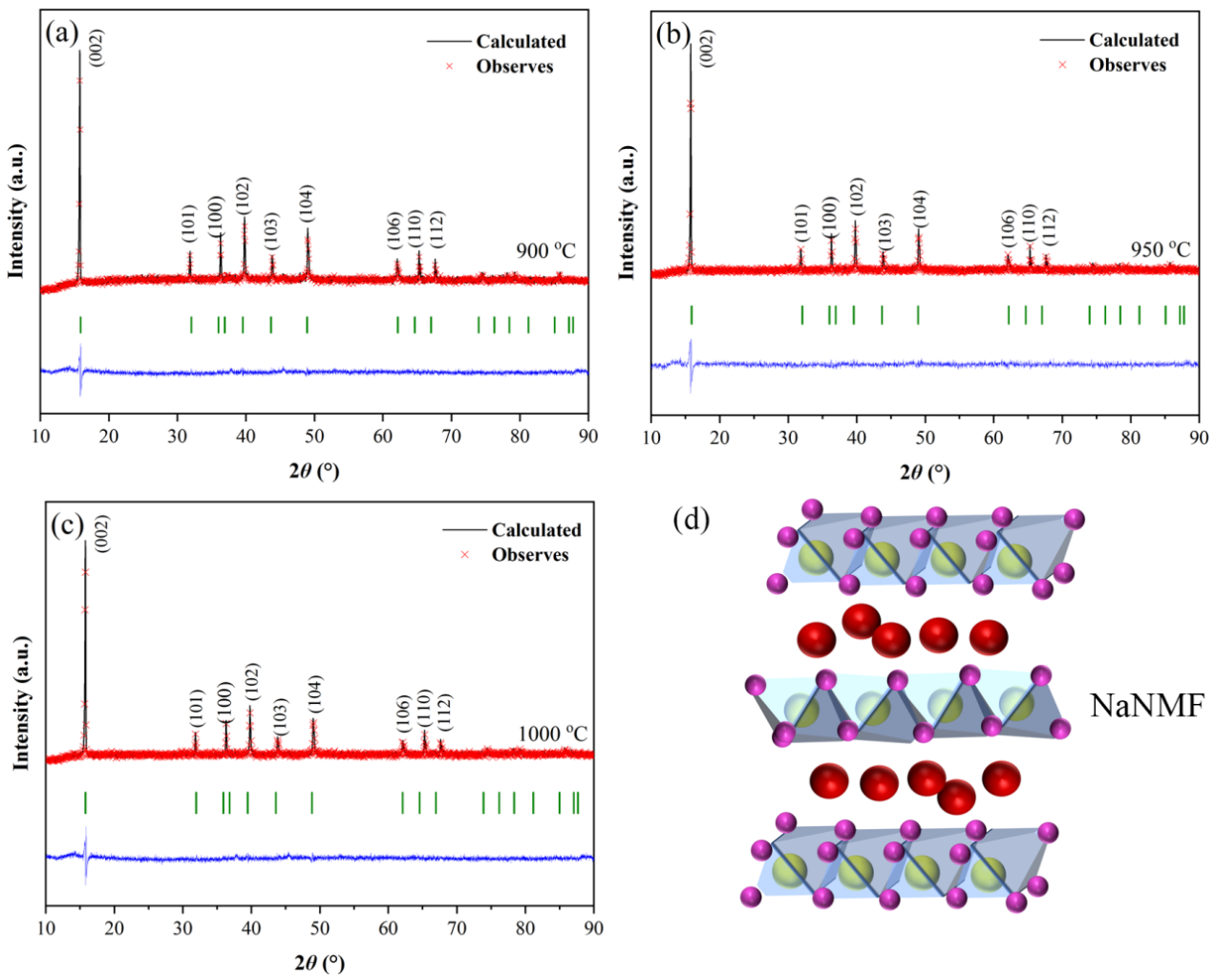

(d)
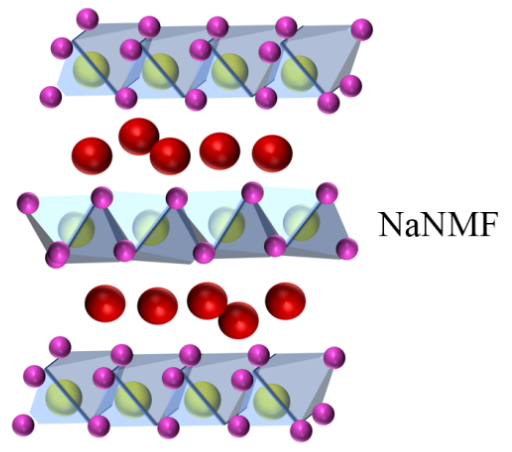

Fig. 2 Refined XRD curves of the NaNMF samples calcinated at (a) $900{ }^{\circ} \mathrm{C}$, (b) $950{ }^{\circ} \mathrm{C}$, (c) $1000{ }^{\circ} \mathrm{C}$, and (d) schematic of refined layered crystal structure of NaNMF.
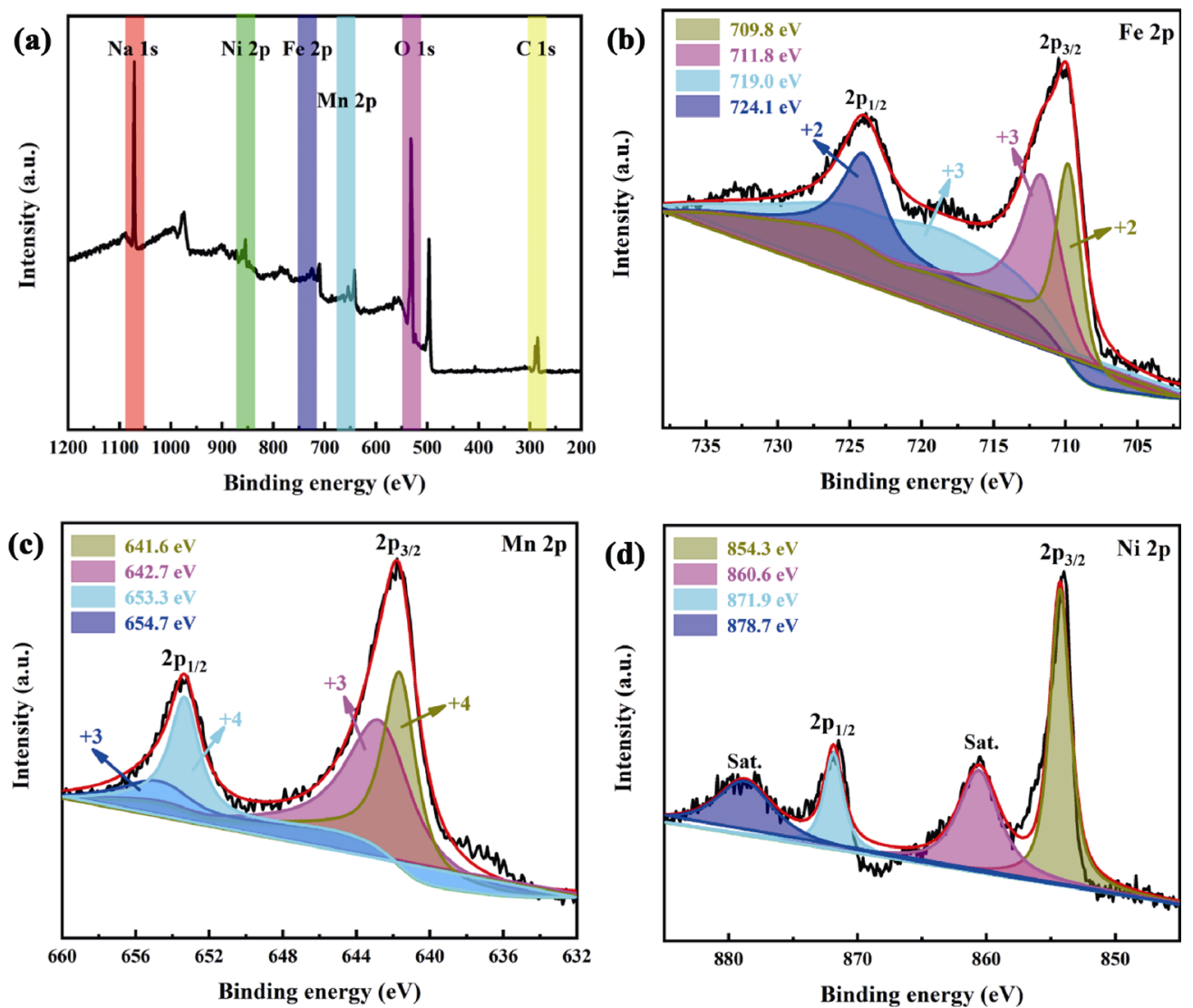

Fig. 3 (a) XPS survey spectra and the high-resolution XPS spectra of (b) Fe 2p, (c) Mn 2p, and (d) Ni 2p for NaNMF-950. 
$710.6 \mathrm{eV}\left(\mathrm{Fe} 2 \mathrm{p}_{3 / 2}\right)$ and $723.4 \mathrm{eV}\left(\mathrm{Fe} 2 \mathrm{p}_{1 / 2}\right)$ demonstrate that the surface oxidation state of Fe was trivalent (3+) in this layered transitionmetal oxide. The results show that the oxidation state of iron is trivalent. Their Mn $2 p$ spectrum shows two main peaks, Mn $2 \mathrm{p}_{3 / 2}$ at about $641.6 \mathrm{eV}$ and $\mathrm{Mn} 2 \mathrm{p}_{1 / 2}$ at $653.3 \mathrm{eV}$, which can be deconvoluted into four characteristic peaks. Peaks appearing at the binding energy of $\sim 642.7$ and $\sim 654.7 \mathrm{eV}$ are related to $\mathrm{Mn}^{4+}$, whereas the binding energy peaks at $\sim 642$ and $\sim 653 \mathrm{eV}$ are related to $\mathrm{Mn}^{3+}$, revealing that $\mathrm{Mn}^{3+}$ and $\mathrm{Mn}^{4+}$ coexist. The five characteristic peaks in the Ni $2 p$ spectrum correspond to the two main peaks of $\mathrm{Ni} 2 \mathrm{p}_{3 / 2}$ and $\mathrm{Ni} 2 \mathrm{p}_{1 / 2}$ at 854.3 and $871.9 \mathrm{eV}$, respectively, the satellite peaks, which means that nickel ions are two prices.

The morphology of the sample was tested using TEM and SEM. The morphologies of the final products of NaNMF-900 and NaNMF-1000, and the elemental distribution in NaNMF-950 are shown in Fig. 4 and Fig. S1 in the ESM. After annealing at 900, 950, and $1000{ }^{\circ} \mathrm{C}$, the spherical particles of the two types of precursors were all divided into rock-shaped particles, as observed in Figs. 4(a)-4(c) and Fig. S1 in the ESM. Both samples have a similar rock-like secondary particle morphology with a particle size distribution between 1 and $3 \mu \mathrm{m}$. Careful observation reveals that the secondary particles of the P2 sample have a clean and smooth surface, and have an obvious crystal edge, which is in agreement with its high crystallinity. As the temperature increases, the particles have a slight tendency to become smaller, but it is not obvious. These results indicate that annealing at different temperatures has no effect on the morphology of the final product. In Fig. 4(g), the energy dispersive X-ray spectrometer (EDS; Zeiss Supra 55, Germany) mappings of NNMF-950 show a uniform distribution of $\mathrm{Na}, \mathrm{Ni}, \mathrm{Mn}$, and $\mathrm{Fe}$. To obtain information on the morphology and structure of the target product NaNMF-950, FE-TEM and HR-TEM were performed on the sample. Figures 4(d)-4(f) with different magnifications display a part of the cube rock-like particle (bright part). The high-resolution TEM (HRTEM) image in Fig. 4(f) shows the layered structure of this material. The (001) P2 structure has a crystal plane spacing of $0.25 \mathrm{~nm}$, indicating the high crystallinity of the sample. TEM and SEM results confirmed the crystallinity of Fe-substituted materials.

The molar ratios of metal ions in the samples were chemically analyzed by inductively coupled plasma atomic-emission spectrometry (ICP-AES) and the $\mathrm{Na}$ molar ratios were determined to be $6.63,6.54$, and 6.47 for NaNMF-900, NaNMF-950, and NaNMF-1000, respectively, which are slightly lower than the initial composition, possibly due to the volatile loss of sodium in the high temperature sintering process (Tables S2-S4
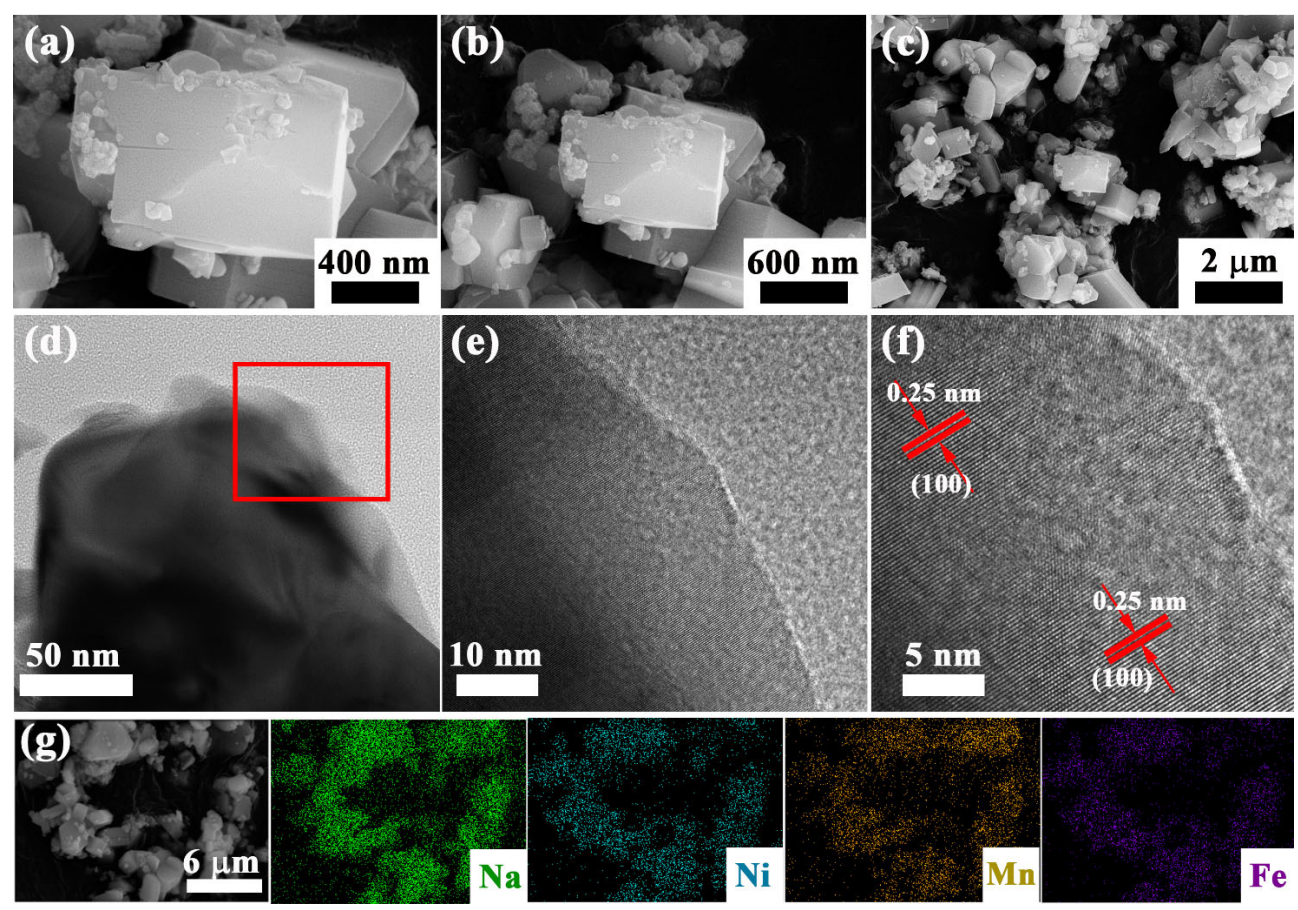

Fig. 4 (a-c) SEM images with gradually increased magnification, (d-f) FE-TEM images with gradually increased magnification, and (g) EDS elemental mappings of NaNMF-950. 
in the ESM). ICP results revealed that " $x$ " values were approximately 0.33 for NaNMF-900, NaNMF-950, and NaNMF-1000, which indicate that the phases formed were sodium deficient phases as expected for P2-type sodium-based cathodes.

To study the effect of iron content and morphology on the performance of SIBs, the electrochemical performance of NaNMF-900, NaNMF-950, and NaNMF-1000 was examined in coin cells using temperature as a reference variable. As shown in Fig. 5(a), NaNMF-900, NaNMF-950, and NaNMF-1000 deliver an initial discharge-specific capacity of $51.9,72.8$, and $60.7 \mathrm{mAh} \cdot \mathrm{g}^{-1}$ in the voltage range of $2.0-4.2 \mathrm{~V}$ at $2.0 \mathrm{C}$. Figure $5(\mathrm{~b})$ shows the galvanostatic charge/discharge curves of the NaNMF-950 sample at $2.0 \mathrm{C}$ for the first three cycles. In the initial cycle, the charge and discharge capacities of the NaNMF-950 sample were 73.5 and $67.8 \mathrm{mAh} \cdot \mathrm{g}^{-1}$, respectively, and the coulombic efficiency reached $91.7 \%$. The plateau of $\sim 3.75 \mathrm{~V}$ appeared in the first discharge and disappeared in the subsequent cycles, most likely because of the formation of the cathodeelectrolyte interface layer, leading to the irreversible capacity in the first cycle.

In the following cycles, the charge/discharge curves almost overlap each other, indicating that the cathode material is reversible. Figure 5(c) compares the rate performance of NaNMF-900, NaNMF-950, and NaNMF1000 particles. The NaNMF-950 sample provides the highest capacity at different current rates from 0.2 to $5 \mathrm{C}$. For the NaNMF-950 sample, the reversible capacities obtained at $0.2,0.5,1.0,2.0$, and $5.0 \mathrm{C}$ were 116.2 , $96.8,83.4,72.9$, and $53.1 \mathrm{mAh} \cdot \mathrm{g}^{-1}$, respectively. A discharge capacity of $53.1 \mathrm{mAh} \cdot \mathrm{g}^{-1}$ can still be achieved, even at a high current density of 5.0 C, which proves the high rate capability of the NaNMF-950 sample. In addition, when the current rate returns to $0.2 \mathrm{C}$, the capacity returns to $113.3 \mathrm{mAh} \cdot \mathrm{g}^{-1}$, indicating that the NaNMF-950 cathode has high reversibility. In contrast, NaNMF-900 and NaNMF-1000 particles showed poor performance at all current rates. Figure 5(d) shows the
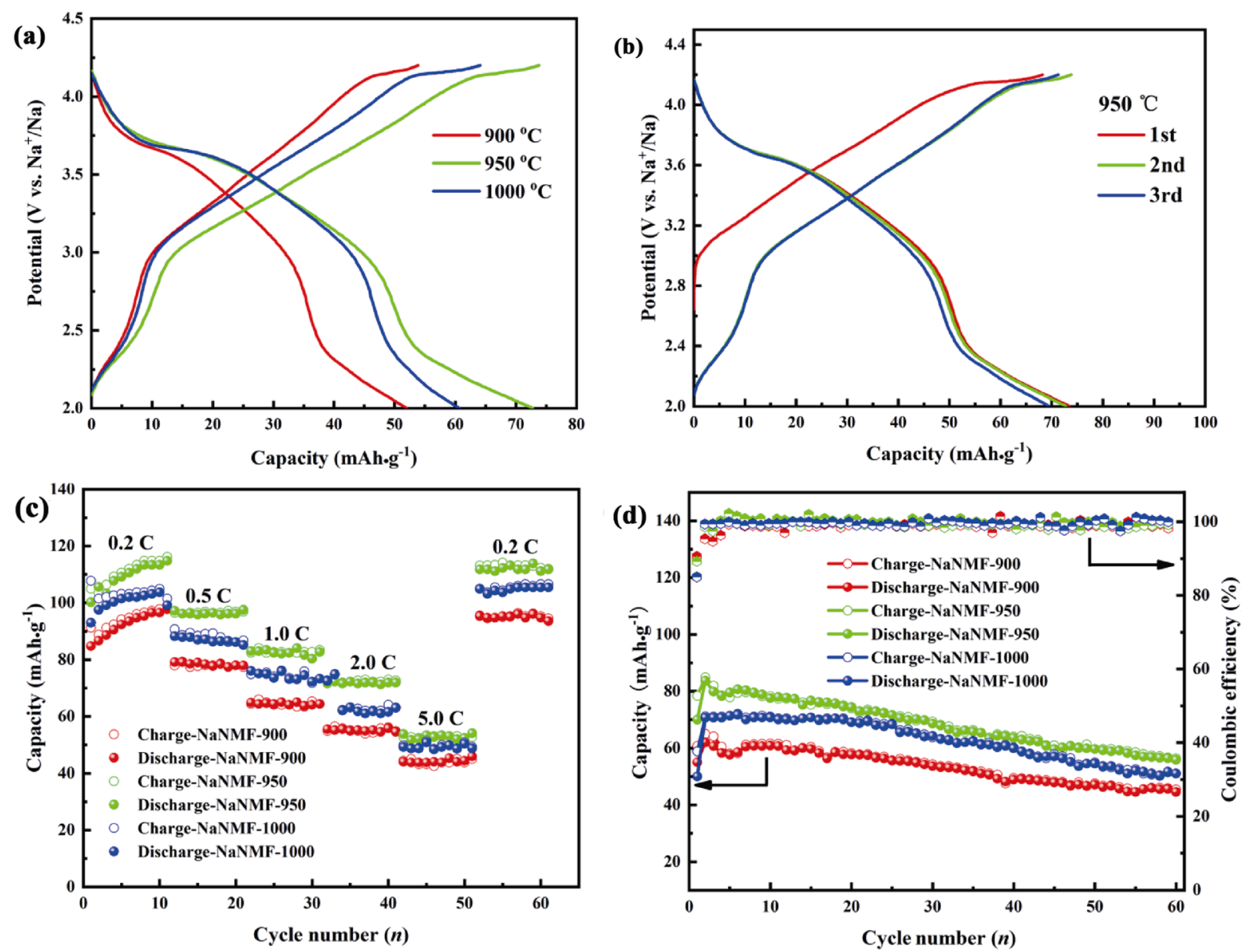

Fig. 5 Electrochemical performance of half battery: (a) charge/discharge profiles between 2.0 and $4.2 \mathrm{~V}$ at a rate of $2.0 \mathrm{C}$, (b) galvanostatic charge/discharge profiles of the NaNMF-950 sample at $2.0 \mathrm{C}$, (c) comparison of the rate performance, and (d) cycling performance of NaNMF-900, NaNMF-950, and NaNMF-1000. 
cycle performance of four samples at 2.0 C, following the same trend: NaNMF-950 > NaNMF-1000 > NaNMF-900. Note that NaNMF-900 particles provide the lowest capacity among the four samples, which means that material design and crystallinity contribute to electrochemical performance. In the cycle test, the capacity retention rate of the NaNMF-950 sample after 60 cycles was $79.8 \%$, which was equivalent to $81.1 \%$ of NaNMF-1000 and was higher than $72.8 \%$ of the NaNMF-900 particle sample.

\section{3 NaNMFA (4-cation oxide)}

The oxidation state of the aluminum of NaNMFA-2 was investigated using XPS (Fig. 6). The XPS spectrum was deconvoluted, and the XPSPEAK software with linear background and Lorentzian-Gaussian function were used for analysis. The $\mathrm{Al} 2 \mathrm{p}$ spectrum is shown in Fig. 6(a). The Al-O bond of the materials at $73.8 \mathrm{eV}$ can be designated $\mathrm{Al}^{3+}$. Fe 2p, Mn 2p, and Ni 2p maintain a similar chemical valence state to the substrate NaNMF, indicating that the increase in cations did not destroy the original chemical composition structure. In addition NaNMFA-2 exhibits almost the same XRD features, and all the diffraction lines are similar to NaNMF (PDF: 00-054-0894), confirming a pure phase of the compound (Fig. S2 in the ESM).

Figures 7(a)-7(c) show the SEM images of the NaNMFA-2 sample. The enlarged SEM image (Fig. 7(d)) shows that the sample has a similar sheet shape stacked to form an overall morphology, with a particle size distribution between 1 and $10 \mu \mathrm{m}$. We found that the surface of the secondary particles was clean and smooth, which was consistent with the high crystallinity. The element distribution of NaNMFA-2 (Fig. 7(d)) was further studied using EDS. The results show that $\mathrm{Ni}$, $\mathrm{Mn}, \mathrm{Fe}$, and $\mathrm{Al}$ are distributed on the surface of NaNMFA-2. To verify the preferred orientation of the NaNMFA-2 sample, HRTEM was used to further investigate the NaNMFA-2 (Fig. 8). A single growth direction can be seen in Figs. 8(c) and 8(d). The crystal
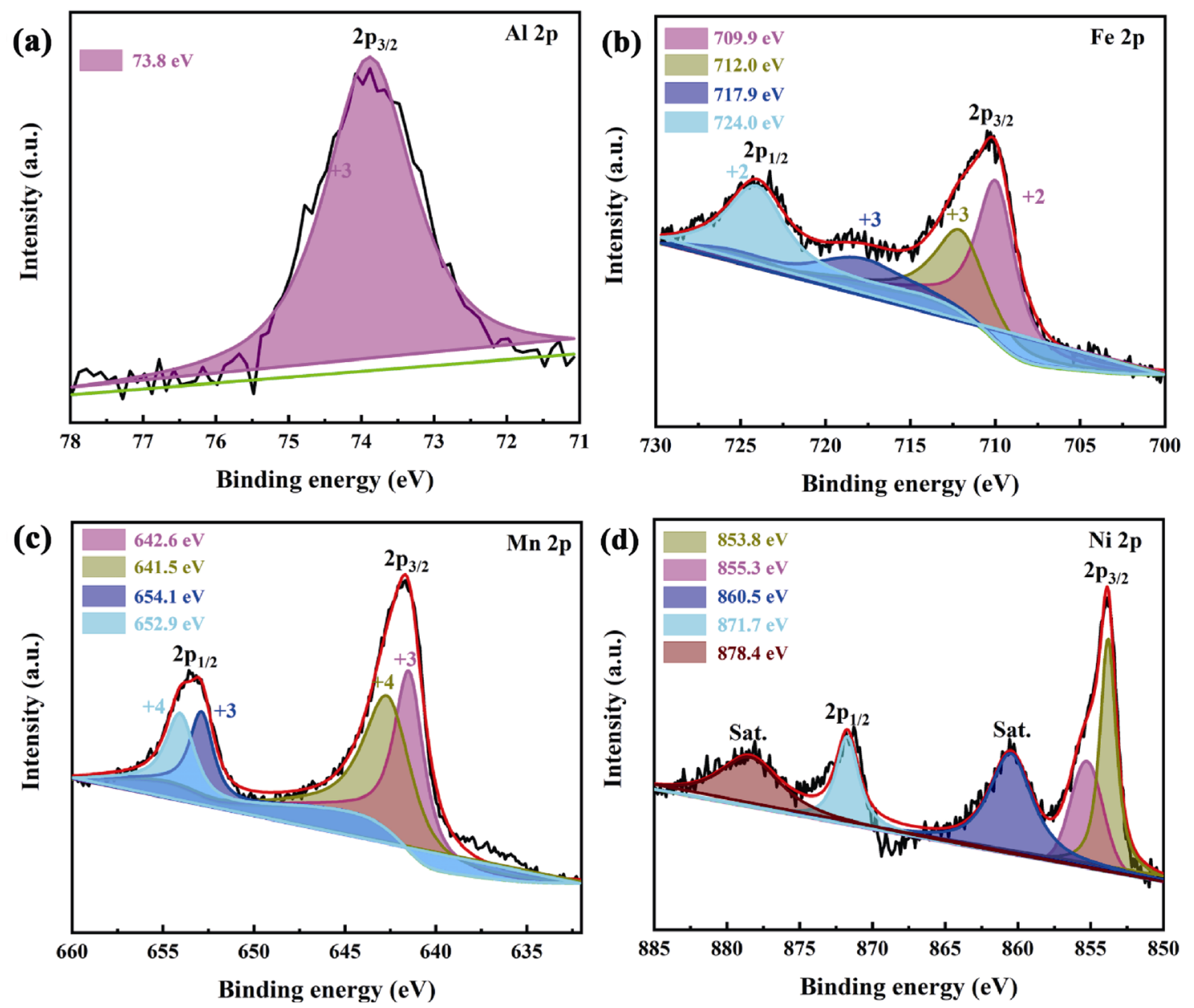

Fig. 6 XPS spectra for the as-prepared NaNMFA-2: (a) Al 2p, (b) Fe 2p, (c) Mn 2p, and (d) Ni 2p. 

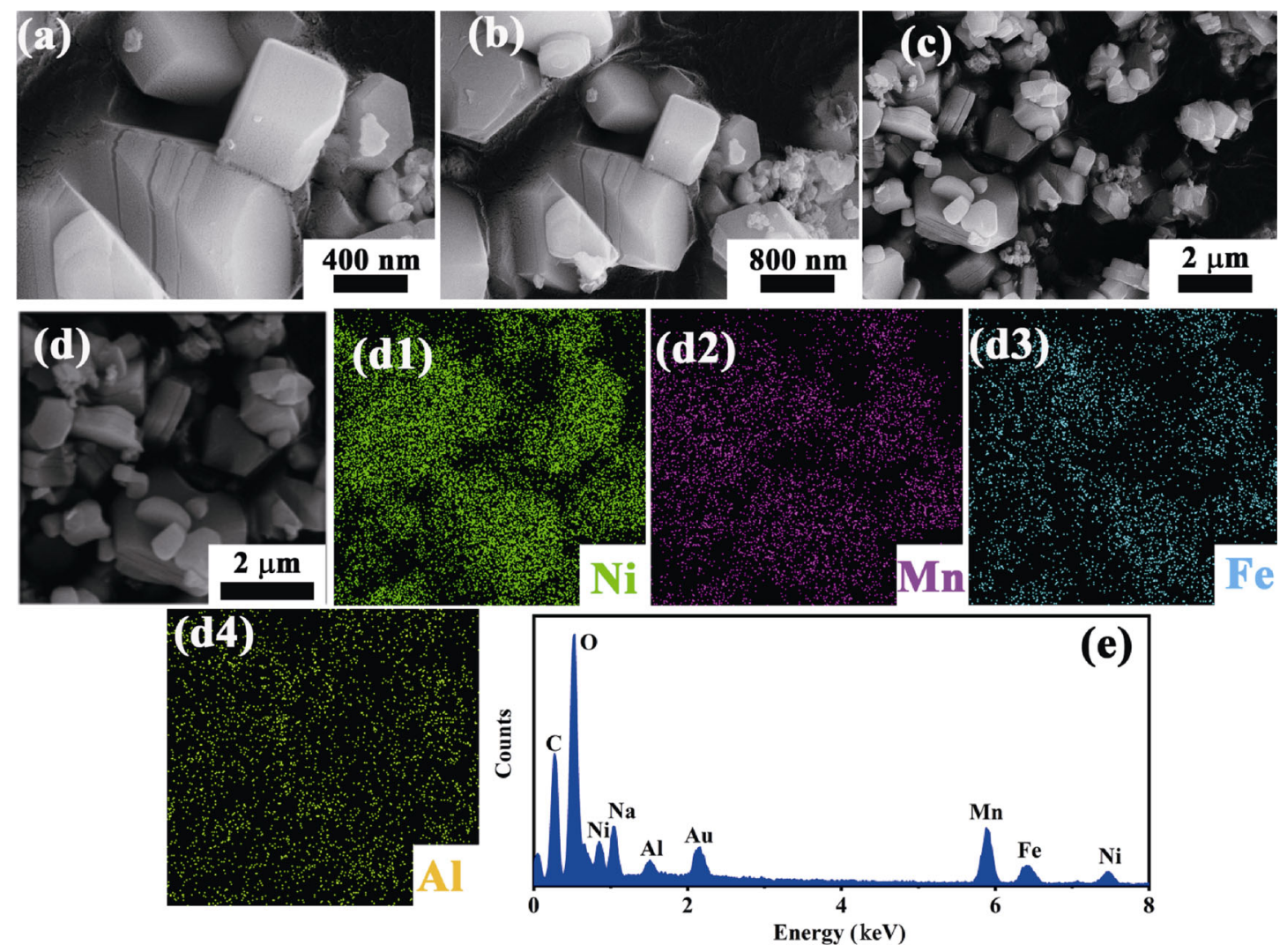

Fig. 7 (a-c) SEM images of NaNMFA-2; (d) EDS mappings of NaNMFA-2: (d1) Ni, (d2) Mn, (d3) Fe, and (d4) Al; and (e) element spectrum of the particle.
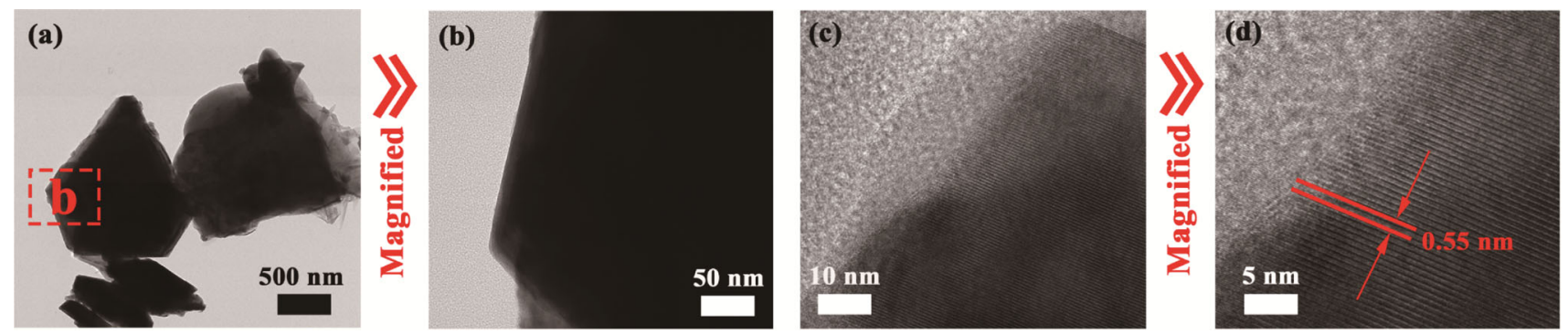

Fig. 8 (a, b) FE-TEM images with gradually increased magnification and (c, d) HR-TEM images.

plane spacing is $0.55 \mathrm{~nm}$, which corresponds to the (002) lattice plane. These measurements show that the largest exposed surface is the $a b$ plane, indicating that the preferred P2-NaNMFA thin film with excellent crystallinity and $c$-axis orientation has been prepared, and is consistent with the XRD results (Fig. 1).

The electrochemical performance was examined using NaNMFA cathode versus $\mathrm{Na}$ metal for the half cell. The cyclic voltammetry (CV) curves of NaNMFA-1, NaNMFA-2, and NaNMFA-3, are shown in Fig. S3 in the ESM, which shows the effect of $\mathrm{Al}$ addition on the electrochemical properties of the materials. The curves of the NaNMFA-1, NaNMFA-2, and NaNMFA-3 samples during the first 3 cycles almost overlap with each other, underlining their reversible electrochemical processes [68]. In addition, the results demonstrate that the potential difference between the anode current peaks and their corresponding cathode peaks is much smaller for NaNMF-1 and NaNMFA-3 samples when compared with NaNMFA-2 sample, which uncovers the lower polarization for the former two Al-doped samples [69,70]. For the NaNMFA-2 sample, seven pairs of oxidation/ reduction peaks can be observed. The main features in the CV curves are two pairs of anodic/cathodic peaks at potentials of $4.2 / 3.5 \mathrm{~V}$, corresponding to the redox reactions of $\mathrm{Fe}^{3+} / \mathrm{Fe}^{4+}$ components [71]. The pair of oxidation/reduction peaks appeared below $2.0 \mathrm{~V}$ can be attributed to the redox reaction of $\mathrm{Mn}^{4+} / \mathrm{Mn}^{3+}[72,73]$. 
Figure 9(a) shows the typical charge and discharge curves of NaNMFA-2 at a current density of $0.2 \mathrm{C}$ in different cut-off voltage windows of 2.0-4.2 V. The initial capacity of the first charging curve is $113.7 \mathrm{mAh} \cdot \mathrm{g}^{-1}$. The initial coulombic efficiency is as high as $80.1 \%$, which has an advantage in sodium-ion semi battery. From the second cycle, the cathode showed a reversible capacity of $105.1 \mathrm{mAh} \cdot \mathrm{g}^{-1}$, equivalent to the extraction/ insertion of $0.44 \mathrm{Na}^{+}$in charge/discharge [74]. Stability and rate capability are two important contrast parameters of high power energy storage devices. Therefore, as shown in Fig. 9(b), all electrodes were tested at varying currents of 0.2 to $5 \mathrm{C}$ between 2.0 and $4.2 \mathrm{~V}$. The charge-transfer rate on the interface determines the capacity retention rate at high magnification [75]. Due to the effect of the crystallinity and element distribution of the original cathode (NaNMFA-1), its performance is lower than many previous reports; however, its electrochemical performance can be improved by increasing the configurational entropy (adding $\mathrm{Al}$ element). When the applied current increases due to insufficient volume diffusion time, the charge and discharge curves are similar, and there is no obvious voltage plateau. At a higher current, the NaNMFA-2 electrode shows better performance than the original electrode. The discharge capacities of the NaNMFA-2 electrode were 125.6, $119.1,110.1,101.2$, and $90.8 \mathrm{mAh} \cdot \mathrm{g}^{-1}$ at $0.2,0.5,1.0$, 2.0, and 5.0 C rates, respectively. The electrochemical performance of NaNMFA-2 is superior to that of many other similar SIB transition-metal-oxide cathode materials, as reported in the literature (Table S5 in the ESM).

Due to polarization, the discharge capacity of all electrodes decreases linearly, with the increase in current density [76]. The stability of NaNMFA-1, NaNMFA-2, and NaNMFA-3 was tested, between 2.0 and $4.2 \mathrm{~V}$, as shown in Fig. 9(c). The capacity of the NaNMFA-2 electrode was higher than $102.8 \mathrm{mAh} \cdot \mathrm{g}^{-1}$, and the capacity retention rate was $89.9 \%$ after 60 cycles, which was higher than that of the other two electrodes.

The EIS of NaNMFA-1, NaNMFA-2, and NaNMFA-3 electrodes was measured as depicted in Fig. 9(d). The exchange current density and impedance values are shown in Table 3. All curves are related to a high-frequency region and a low-frequency region. The high-frequency
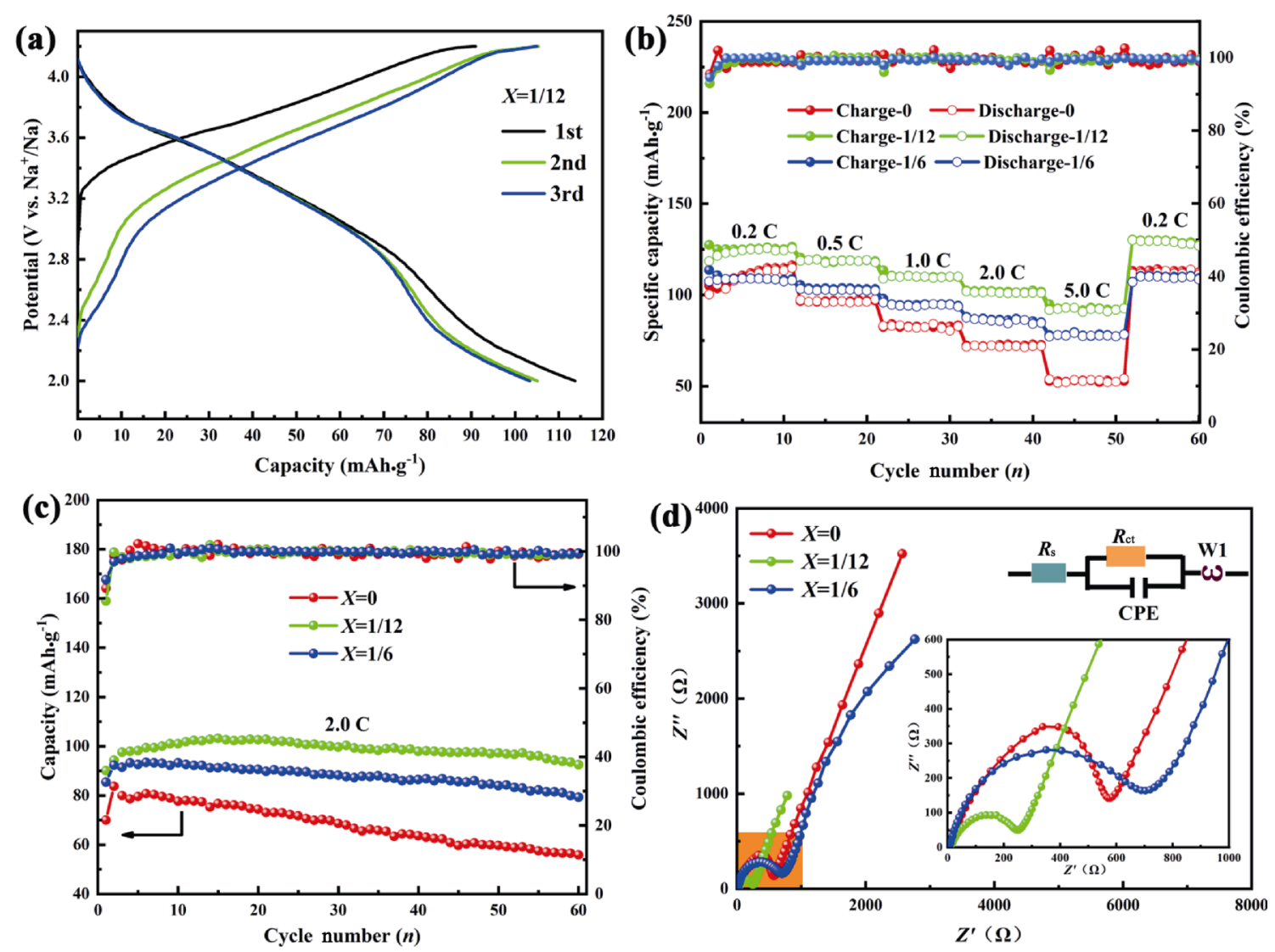

Fig. 9 (a) Charge/discharge profiles of NaNMFA-2 between 2.0 and $4.2 \mathrm{~V}$ at $0.5 \mathrm{C}$, (b) rate performance of the as-prepared materials, (c) long-term cycling performance of the materials at $2.0 \mathrm{C}$ in the initial 60 cycles, and (d) Nyquist impedance spectra and equivalent circuit. 
Table 3 Electrochemical properties of NaNMFA-1, NaNMFA-2, and NaNMFA-3 materials from EIS

\begin{tabular}{cccc}
\hline Sample & $R_{\mathrm{s}}(\Omega)$ & $R_{\mathrm{ct}}(\Omega)$ & $j\left(\mathrm{~mA} \cdot \mathrm{cm}^{-2}\right)$ \\
\hline NaNMFA-1 & 679.5 & 50.3 & $5.1 \times 10^{-3}$ \\
NaNMFA-2 & 302.3 & 56.1 & $4.6 \times 10^{-3}$ \\
NaNMFA-3 & 938.1 & 82.3 & $3.1 \times 10^{-4}$ \\
\hline
\end{tabular}

region is attributed to the ohmic resistance $\left(R_{\mathrm{S}}\right)$ at the electrode-electrolyte interface, whereas the semicircle in the high-frequency region is related to the chargetransfer resistance $\left(R_{\mathrm{ct}}\right)$ at the active material interface [77]. The oblique line in the low-frequency region is the response of the bulk $\mathrm{Na}^{+}$diffusion of the active material, i.e., the waugh impedance. The NaNMFA-2 electrode displayed the lowest $R_{\mathrm{ct}}(56.1 \Omega)$, lower than that of the pristine NaNMFA-3 (82.3 $\Omega$ ) and similar to that of NaNMFA-1 (50.3 $\Omega$ ) electrodes. In addition, according to the formula $\left(j=R T /\left(n F R_{\mathrm{ct}}\right)\right)$, the higher exchange current density of the NaNMFA-2 electrode was due to the lower charge-transfer resistance (Table 3) [78].

The highest exchange current density $\left(j=5.1 \times 10^{-3}\right.$ $\mathrm{mA} \cdot \mathrm{cm}^{-2}$ ) was obtained using NaNMFA-1 electrode, which was about 16 times that of NaNMFA-3 $(j=4.6 \times$ $\left.10^{-4} \mathrm{~mA}^{\cdot} \mathrm{cm}^{-2}\right)$ and similar to that of NaNMFA-2 $(j=$ $4.6 \times 10^{-3} \mathrm{~mA}^{-} \mathrm{cm}^{-2}$ ). However, $\mathrm{Al}$ reduces the ohmic resistance of the material, and the order of $R_{\mathrm{s}}$ is NaNMFA-3 < NaNMFA-1 < NaNMFA-2. Therefore, NaNMFA-2 can make the charge transfer on the electrode-electrolyte interface easier, thus reducing the internal resistance of the entire battery. In addition, the experimental results are consistent with the recyclability and high capacity of NaNMFA-2.

Based on the above analysis, the best rate performance and cycle stability of NaNMFA-2 can be attributed to two reasons: Compared with NaNMFA-1 sample, NaNMFA-2 and NaNMFA-3 samples may have aluminum elements due to the increase in configurational entropy. It has a limiting effect on the multiphase transformation, and has better rate performance and cycle stability during the working process; in addition, in the same cationic configuration system, with the increase in the aluminum content (NaNMFA-3), the performance will decrease. This may be caused by excessive doping of $\mathrm{Al}$ at the octahedral position, which causes the $\mathrm{Na}^{+}$diffusion path to occupy the lattice dislocations. Therefore, for NaNMFA-2, higher sodium-ion transfer resistance can be expected. In recent years, research on layered cathode oxide for battery applications has attracted a lot of attention defining a new emerging research direction. The development of energy storage materials based on medium entropy layered cathode oxide multi-anionic and multicationic systems is rapidly expanding. In addition to the above two factors, it also includes: (1) The myriad of elemental compositions are available; (2) the composition is free from toxic or rare elements; and (3) the high-entropy stabilization effects enable a relatively simple synthesis route contributing to unexpected electrochemical performance. According to current research reports, high-entropy ceramic oxide shows excellent electrochemical properties, such as high-specific capacity and good cycle stability and reversibility. All these aspects suggest that the emerging research on medium-entropy ceramic oxide offers unexplored opportunities to simultaneously improve performance, safety, and durability of reversible energy storage systems.

\section{Conclusions}

In summary, a series of P2 layered NaNMF and NaNMFA materials have been synthesized using the one-step solid-phase method. When used as a cathode material for SIBs, NaNMFA exhibits excellent electrochemical performance in terms of rate reversibility, cycle stability, and capacity. After 60 cycles, the P2 structure of NaMFA-2 remained good. The experimental results show that the increase in configuration entropy makes the chargedischarge curves smoother, and it can make the crystal structure more stable and inhibit the complex phase transition of $\mathrm{Mn}^{3+}$ during the continuous $\mathrm{Na}$ intercalation/ delamination process. The electrochemical performance test results show that the medium-entropy strategy will provide new opportunities for the preparation of advanced layered cathode materials.

\section{Acknowledgements}

This work was financially supported by the National Natural Science Foundation of China (Nos. 51674068, 51874079, 51804035, and 11775226), the Natural Science Foundation of Hebei Province (No. E2018501091), the Hebei Province Key Research and Development Plan Project (No. 19211302D), the Fundamental Research Funds for the Central Universities (Nos. N172302001, N182306001, N182312007, N182304018, and N2023040), and the Research Project on the Distribution of Heavy Metals in Soil and Comprehensive Utilization Technology of 
Tailings in Typical Iron Tailing Reservoir Areas of Hebei Province (No. 802060671901).

\section{Electronic Supplementary Material}

Supplementary material is available in the online version of this article at https://doi.org/10.1007/s40145-021-0524-8.

\section{References}

[1] Yabuuchi N, Kubota K, Dahbi M, et al. Research development on sodium-ion batteries. Chem Rev 2014, 114: 11636-11682.

[2] Yi TF, Pan JJ, Wei TT, et al. $\mathrm{NiCo}_{2} \mathrm{~S}_{4}$-based nanocomposites for energy storage in supercapacitors and batteries. Nano Today 2020, 33: 100894.

[3] Titirici MM. Sustainable batteries - quo vadis? Adv Energy Mater 2021, 11: 2003700.

[4] Armand M, Tarascon JM. Building better batteries. Nature 2008, 451: 652-657.

[5] Hwang JY, Myung ST, Sun YK. Sodium-ion batteries: Present and future. Chem Soc Rev 2017, 46: 3529-3614.

[6] Yi TF, Wei TT, Li Y, et al. Efforts on enhancing the Li-ion diffusion coefficient and electronic conductivity of titanatebased anode materials for advanced Li-ion batteries. Energy Storage Mater 2020, 26: 165-197.

[7] Hou HS, Banks CE, Jing MJ, et al. Carbon quantum dots and their derivative $3 \mathrm{D}$ porous carbon frameworks for sodium-ion batteries with ultralong cycle life. Adv Mater 2015, 27: 7861-7866.

[8] Hou HS, Shao LD, Zhang Y, et al. Large-area carbon nanosheets doped with phosphorus: A high-performance anode material for sodium-ion batteries. $A d v$ Sci 2017, 4: 1600243.

[9] Hong WW, Zhang Y, Yang L, et al. Carbon quantum dot micelles tailored hollow carbon anode for fast potassium and sodium storage. Nano Energy 2019, 65: 104038.

[10] Wu CJ, Hua WB, Zhang Z, et al. Design and synthesis of layered $\mathrm{Na}_{2} \mathrm{Ti}_{3} \mathrm{O}_{7}$ and tunnel $\mathrm{Na}_{2} \mathrm{Ti}_{6} \mathrm{O}_{13}$ hybrid structures with enhanced electrochemical behavior for sodium-ion batteries. Adv Sci 2018, 5: 1800519.

[11] Xiao Y, Wang PF, Yin YX, et al. Exposing $\{010\}$ active facets by multiple-layer oriented stacking nanosheets for high-performance capacitive sodium-ion oxide cathode. Adv Mater 2018, 30: 1803765.

[12] Xiao Y, Zhu YF, Xiang W, et al. Deciphering an abnormal layered-tunnel heterostructure induced by chemical substitution for the sodium oxide cathode. Angew Chemie Int Ed 2020, 59: 1491-1495.

[13] You Y, Manthiram A. Progress in high-voltage cathode materials for rechargeable sodium-ion batteries. $A d v$ Energy Mater 2018, 8: 1701785.

[14] Clément RJ, Bruce PG, Grey CP. Review-Manganese-based P2-type transition metal oxides as sodium-ion battery cathode materials. J Electrochem Soc 2015, 162: A2589A2604.

[15] Ma C, Alvarado J, Xu J, et al. Exploring oxygen activity in the high energy P2-type $\mathrm{Na}_{0.78} \mathrm{Ni}_{0.23} \mathrm{Mn}_{0.69} \mathrm{O}_{2}$ cathode material for Na-ion batteries. J Am Chem Soc 2017, 139: 4835-4845.

[16] Maitra U, House RA, Somerville JW, et al. Oxygen redox chemistry without excess alkali-metal ions in $\mathrm{Na}_{2 / 3}\left[\mathrm{Mg}_{0.28} \mathrm{Mn}_{0.72}\right] \mathrm{O}_{2}$. Nat Chem 2018, 10: 288-295.

[17] Rong XH, Liu J, Hu EY, et al. Structure-induced reversible anionic redox activity in Na layered oxide cathode. Joule 2018, 2: 125-140.

[18] Zhao QQ, Butt FK, Guo ZF, et al. High-voltage P2-type manganese oxide cathode induced by titanium gradient modification for sodium ion batteries. Chem Eng $J$ 2021, 403: 126308.

[19] Wang PF, Yao HR, Liu XY, et al. $\mathrm{Na}^{+} /$vacancy disordering promises high-rate Na-ion batteries. Sci Adv 2018, 4: eaar6018.

[20] Wang QC, Meng JK, Yue XY, et al. Tuning P2-structured cathode material by $\mathrm{Na}$-site $\mathrm{Mg}$ substitution for $\mathrm{Na}$-ion batteries. J Am Chem Soc 2019, 141: 840-848.

[21] Wang PF, You Y, Yin YX, et al. Suppressing the P2-O2 phase transition of $\mathrm{Na}_{0.67} \mathrm{Mn}_{0.67} \mathrm{Ni}_{0.33} \mathrm{O}_{2}$ by magnesium substitution for improved sodium-ion batteries. Angewandte Chemie 2016, 128: 7571-7575.

[22] Singh G, Tapia-Ruiz N, Lopez del Amo JM, et al. High voltage Mg-doped $\mathrm{Na}_{0.67} \mathrm{Ni}_{0.3-x} \mathrm{Mg}_{x} \mathrm{Mn}_{0.7} \mathrm{O}_{2}(x=0.05,0.1)$ $\mathrm{Na}$-ion cathodes with enhanced stability and rate capability. Chem Mater 2016, 28: 5087-5094.

[23] Huang Q, Liu JT, Xu S, et al. Roles of coherent interfaces on electrochemical performance of sodium layered oxide cathodes. Chem Mater 2018, 30: 4728-4737.

[24] Ma C, Alvarado J, Xu J, et al. Exploring oxygen activity in the high energy P2-type $\mathrm{Na}_{0.78} \mathrm{Ni}_{0.23} \mathrm{Mn}_{0.69} \mathrm{O}_{2}$ cathode material for Na-ion batteries. J Am Chem Soc 2017, 139: 4835-4845.

[25] Zheng LM, Wang ZQ, Wu MS, et al. Jahn-Teller type small polaron assisted $\mathrm{Na}$ diffusion in $\mathrm{NaMnO}_{2}$ as a cathode material for Na-ion batteries. J Mater Chem A 2019, 7: 6053-6061.

[26] Hwang JY, Kim J, Yu TY, et al. A new P2-type layered oxide cathode with superior full-cell performances for K-ion batteries. J Mater Chem A 2019, 7: 21362-21370.

[27] Kumakura S, Tahara Y, Kubota K, et al. Sodium and manganese stoichiometry of P2-type $\mathrm{Na}_{2 / 3} \mathrm{MnO}_{2}$. Angew Chem Int Ed 2016, 55: 12760-12763.

[28] $\mathrm{Wu} \mathrm{XH}$, Guo JH, Wang DW, et al. P2-type $\mathrm{Na}_{0.66} \mathrm{Ni}_{0.33-x} \mathrm{Zn}_{x} \mathrm{Mn}_{0.67} \mathrm{O}_{2}$ as new high-voltage cathode materials for sodium-ion batteries. J Power Sources 2015, 281: 18-26.

[29] You Y, Xin S, Asl HY, et al. Insights into the improved high-voltage performance of $\mathrm{Li}$-incorporated layered oxide cathodes for sodium-ion batteries. Chem 2018, 4: 21242139. 
[30] Huang WN, Xing LD, Zhang RQ, et al. A novel electrolyte additive for improving the interfacial stability of high voltage lithium nickel manganese oxide cathode. J Power Sources 2015, 293: 71-77.

[31] Put B, Vereecken PM, Labyedh N, et al. High cycling stability and extreme rate performance in nanoscaled $\mathrm{LiMn}_{2} \mathrm{O}_{4}$ thin films. ACS Appl Mater Interfaces 2015, 7: 22413-22420.

[32] Zhao WW, Kirie H, Tanaka A, et al. Synthesis of metal ion substituted $\mathrm{P} 2-\mathrm{Na}_{2 / 3} \mathrm{Ni}_{1 / 3} \mathrm{Mn}_{2 / 3} \mathrm{O}_{2}$ cathode material with enhanced performance for $\mathrm{Na}$ ion batteries. Mater Lett 2014, 135: 131-134.

[33] Hemalatha K, Jayakumar M, Bera $\mathrm{P}$, et al. Improved electrochemical performance of $\mathrm{Na}_{0.67} \mathrm{MnO}_{2}$ through $\mathrm{Ni}$ and $\mathrm{Mg}$ substitution. J Mater Chem A 2015, 3: 20908-20912.

[34] Wu XH, Guo JH, Wang DW, et al. P2-type $\mathrm{Na}_{0.66} \mathrm{Ni}_{0.33-x} \mathrm{Zn}_{x} \mathrm{Mn}_{0.67} \mathrm{O}_{2}$ as new high-voltage cathode materials for sodium-ion batteries. J Power Sources 2015, 281: 18-26.

[35] Chung KY, Yoon WS, Lee HS, et al. Comparative studies between oxygen-deficient $\mathrm{LiMn}_{2} \mathrm{O}_{4}$ and Al-doped $\mathrm{LiMn}_{2} \mathrm{O}_{4}$. $J$ Power Sources 2005, 146: 226-231.

[36] Clément RJ, Billaud J, Robert Armstrong A, et al. Structurally stable Mg-doped $\mathrm{P} 2-\mathrm{Na}_{2 / 3} \mathrm{Mn}_{1-y} \mathrm{Mg}_{y} \mathrm{O}_{2}$ sodium-ion battery cathodes with high rate performance: Insights from electrochemical, NMR and diffraction studies. Energy Environ Sci 2016, 9: 3240-3251.

[37] Luo C, Langrock A, Fan XL, et al. P2-type transition metal oxides for high performance Na-ion battery cathodes. $J$ Mater Chem A 2017, 5: 18214-18220.

[38] Ramasamy HV, Kaliyappan K, Thangavel R, et al. $\mathrm{Cu}$-doped P2- $\mathrm{Na}_{0.5} \mathrm{Ni}_{0.33} \mathrm{Mn}_{0.67} \mathrm{O}_{2}$ encapsulated with $\mathrm{MgO}$ as a novel high voltage cathode with enhanced Na-storage properties. J Mater Chem A 2017, 5: 8408-8415.

[39] Bucher N, Hartung S, Franklin JB, et al. $\mathrm{P} 2-\mathrm{Na}_{x} \mathrm{Co}_{y} \mathrm{Mn}_{1-y} \mathrm{O}_{2}$ $(y=0,0.1)$ as cathode materials in sodium-ion batteries-Effects of doping and morphology to enhance cycling stability. Chem Mater 2016, 28: 2041-2051.

[40] Kong WJ, Wang HB, Zhai YW, et al. Enhancing the rate capability and cycling stability of $\mathrm{Na}_{0.67} \mathrm{Mn}_{0.7} \mathrm{Fe}_{0.2} \mathrm{Co}_{0.1} \mathrm{O}_{2}$ through a synergy of $\mathrm{Zr}^{4+}$ doping and $\mathrm{ZrO}_{2}$ coating. J Phys Chem C 2018, 122: 25909-25916.

[41] Pang WL, Zhang XH, Guo JZ, et al. P2-type $\mathrm{Na}_{23} \mathrm{Mn}_{1-x} \mathrm{Al}_{x} \mathrm{O}_{2}$ cathode material for sodium-ion batteries: Al-doped enhanced electrochemical properties and studies on the electrode kinetics. J Power Sources 2017, 356: 80-88.

[42] $\mathrm{Wu} \mathrm{X,} \mathrm{Xu} \mathrm{GL,} \mathrm{Zhong} \mathrm{G,} \mathrm{et} \mathrm{al.} \mathrm{Insights} \mathrm{into} \mathrm{the} \mathrm{effects} \mathrm{of}$ zinc doping on structural phase transition of P2-type sodium nickel manganese oxide cathodes for high-energy sodium ion batteries. ACS Appl Mater Interfaces 2016, 8: 22227-22237.

[43] Yuan DD, $\mathrm{Hu} \mathrm{XH}$, Qian JF, et al. P2-type $\mathrm{Na}_{0.67} \mathrm{Mn}_{0.65} \mathrm{Fe}_{0.2} \mathrm{Ni}_{0.15} \mathrm{O}_{2}$ cathode material with High-capacity for sodium-ion battery. Electrochimica Acta 2014, 116: 300-305.
[44] Wang $\mathrm{K}, \mathrm{Wu} \mathrm{ZG}$, Zhang $\mathrm{T}$, et al. P2-type $\mathrm{Na}_{0.67} \mathrm{Mn}_{0.72} \mathrm{Ni}_{0.14} \mathrm{Co}_{0.14} \mathrm{O}_{2}$ with $\mathrm{K}^{+}$doping as new high rate performance cathode material for sodium-ion batteries. Electrochimica Acta 2016, 216: 51-57.

[45] Zhao CL, Ding FX, Lu YX, et al. High-entropy chemistry stabilizing layered O3-type structure in Na-ion cathode. Angew Chem Int Ed 2020, 59: 264-269.

[46] Zhao ZF, Xiang HM, Chen $\mathrm{H}$, et al. High-entropy $\left(\mathrm{Nd}_{0.2} \mathrm{Sm}_{0.2} \mathrm{Eu}_{0.2} \mathrm{Y}_{0.2} \mathrm{Yb}_{0.2}\right)_{4} \mathrm{Al}_{2} \mathrm{O}_{9}$ with good high temperature stability, low thermal conductivity, and anisotropic thermal expansivity. J Adv Ceram 2020, 9: 595-605.

[47] Wang QS, Sarkar A, Wang D, et al. Multi-anionic and -cationic compounds: New high entropy materials for advanced Li-ion batteries. Energy Environ Sci 2019, 12: 2433-2442.

[48] Castle E, Csanádi T, Grasso S, et al. Processing and properties of high-entropy ultra-high temperature carbides. Sci Rep 2018, 8: 8609.

[49] Gild J, Zhang YY, Harrington T, et al. High-entropy metal diborides: A new class of high-entropy materials and a new type of ultrahigh temperature ceramics. Sci Rep 2016, 6: 37946.

[50] Tsai CW, Lai SW, Cheng KH, et al. Strong amorphization of high-entropy AlBCrSiTi nitride film. Thin Solid Films 2012, 520: 2613-2618.

[51] Liu RH, Chen HY, Zhao KP, et al. Entropy as a gene-like performance indicator promoting thermoelectric materials. Adv Mater 2017, 29: 1702712.

[52] Sarkar A, Djenadic R, Wang D, et al. Rare earth and transition metal based entropy stabilised perovskite type oxides. J Eur Ceram Soc 2018, 38: 2318-2327.

[53] Qiu N, Chen H, Yang ZM, et al. A high entropy oxide $\left(\mathrm{Mg}_{0.2} \mathrm{Co}_{0.2} \mathrm{Ni}_{0.2} \mathrm{Cu}_{0.2} \mathrm{Zn}_{0.2} \mathrm{O}\right)$ with superior lithium storage performance. J Alloys Compd 2019, 777: 767-774.

[54] Tietz F, Fronia C. Polyanionic lattice modifications leading to high-entropy sodium ion conductors: Mathematical solution of accessible compositions. ChemPhysChem 2020, 21: 2096-2103.

[55] Ma YJ, Ma Y, Dreyer SL, et al. High-entropy metal-organic frameworks for highly reversible sodium storage. $A d v$ Mater 2021, 33: 2101342.

[56] Usharani NJ, Shringi R, Sanghavi H, et al. Role of size, alio-/multi-valency and non-stoichiometry in the synthesis of phase-pure high entropy oxide (Co, Cu, Mg,Na,Ni,Zn)O. Dalton Trans 2020, 49: 7123-7132.

[57] Yang LF, Chen C, Xiong S, et al. Multiprincipal component $\mathrm{P} 2-\mathrm{Na}_{0.6}\left(\mathrm{Ti}_{0.2} \mathrm{Mn}_{0.2} \mathrm{Co}_{0.2} \mathrm{Ni}_{0.2} \mathrm{Ru}_{0.2}\right) \mathrm{O}_{2}$ as a high-rate cathode for sodium-ion batteries. JACS Au 2021, 1: 98-107.

[58] Wang JB, Cui YY, Wang QS, et al. Lithium containing layered high entropy oxide structures. Sci Rep 2020, 10: 18430.

[59] Sarkar A, Wang QS, Schiele A, et al. High-entropy oxides: Fundamental aspects and electrochemical properties. $A d v$ Mater 2019, 31: 1970189.

[60] Rost CM, Sachet E, Borman T, et al. Entropy-stabilized 
oxides. Nat Commun 2015, 6: 8485.

[61] Sarkar A, Breitung B, Hahn H. High entropy oxides: The role of entropy, enthalpy and synergy. Scripta Mater 2020 , 187: 43-48.

[62] Sarkar A, Breitung B, Hahn H. High entropy oxides: The role of entropy, enthalpy and synergy. Scripta Mater 2020, 187: 43-48.

[63] Chen YW, Fu HY, Huang YY, et al. Opportunities for high-entropy materials in rechargeable batteries. ACS Mater Lett 2021, 3: 160-170.

[64] Amiri A, Shahbazian-Yassar R. Recent progress of high-entropy materials for energy storage and conversion. J Mater Chem A 2021, 9: 782-823.

[65] Yeh JW, Chen SK, Lin SJ, et al. Nanostructured high-entropy alloys with multiple principal elements: Novel alloy design concepts and outcomes. Adv Eng Mater 2004, 6: 299-303.

[66] Ruffa AR. Thermal potential, mechanical instability, and melting entropy. Phys Rev B 1982, 25: 5895-5900.

[67] Yeh JW. Alloy design strategies and future trends in high-entropy alloys. JOM 2013, 65: 1759-1771.

[68] Bao S, Luo SH, Wang ZY, et al. Novel P2-type concentration-gradient $\mathrm{Na}_{0.67} \mathrm{Ni}_{0.167} \mathrm{Co}_{0.167} \mathrm{Mn}_{0.67} \mathrm{O}_{2}$ modified by $\mathrm{Mn}$-rich surface as cathode material for sodium ion batteries. J Power Sources 2018, 396: 404-411.

[69] Yuan DD, He W, Pei F, et al. Synthesis and electrochemical behaviors of layered $\mathrm{Na}_{0.67}\left[\mathrm{Mn}_{0.65} \mathrm{Co}_{0.2} \mathrm{Ni}_{0.15}\right] \mathrm{O}_{2}$ microflakes as a stable cathode material for sodium-ion batteries. $J$ Mater Chem A 2013, 1: 3895.

[70] Hou PY, Yin JM, Lu XH, et al. A stable layered P3/P2 and spinel intergrowth nanocomposite as a long-life and high-rate cathode for sodium-ion batteries. Nanoscale 2018, 10: 6671-6677.

[71] Thorne JS, Dunlap RA, Obrovac MN. Structure and electrochemistry of $\mathrm{Na}_{x} \mathrm{Fe}_{x} \mathrm{Mn}_{1-x} \mathrm{O}_{2}(1.0 \leq x \leq 0.5)$ for $\mathrm{Na}$-ion battery positive electrodes. J Electrochem Soc 2012, 160: A361-A367.

[72] Yu TY, Hwang JY, Aurbach D, et al. Microsphere $\mathrm{Na}_{0.65}\left[\mathrm{Ni}_{0.17} \mathrm{Co}_{0.1} 1 \mathrm{Mn}_{0.72}\right] \mathrm{O}_{2}$ cathode material for high-performance sodium-ion batteries. ACS Appl Mater Interfaces 2017, 9: 44534-44541.
[73] Li ZY, Gao R, Sun LM, et al. Designing an advanced $\mathrm{P} 2-\mathrm{Na}_{0.67} \mathrm{Mn}_{0.65} \mathrm{Ni}_{0.2} \mathrm{Co}_{0.15} \mathrm{O}_{2}$ layered cathode material for Na-ion batteries. J Mater Chem A 2015, 3: 16272-16278.

[74] Zhou YN, Wang PF, Niu YB, et al. A P2/P3 composite layered cathode for high-performance $\mathrm{Na}$-ion full batteries. Nano Energy 2019, 55: 143-150.

[75] Ramasamy HV, N Didwal P, Sinha S, et al. Atomic layer deposition of $\mathrm{Al}_{2} \mathrm{O}_{3}$ on $\mathrm{P} 2-\mathrm{Na}_{0.5} \mathrm{Mn}_{0.5} \mathrm{Co}_{0.5} \mathrm{O}_{2}$ as interfacial layer for high power sodium-ion batteries. $J$ Colloid Interface Sci 2020, 564: 467-477.

[76] Zhou CJ, Yang LC, Zhou CG, et al. Co-substitution enhances the rate capability and stabilizes the cyclic performance of O3-type cathode $\mathrm{NaNi}_{0.45-x} \mathrm{Mn}_{0.25} \mathrm{Ti}_{0.3} \mathrm{Co}_{x} \mathrm{O}_{2}$ for sodium-ion storage at high voltage. ACS Appl Mater Interfaces 2019, 11: 7906-7913.

[77] Yan SX, Luo SH, Feng J, et al. Rational design of flower-like $\mathrm{FeCo}_{2} \mathrm{~S}_{4} /$ reduced graphene oxide films: Novel binder-free electrodes with ultra-high conductivity flexible substrate for high-performance all-solid-state pseudocapacitor. Chem Eng J 2020, 381: 122695.

[78] Zhang QY, Zhang CL, Li B, et al. Preparation and characterization of $\mathrm{W}$-doped $\mathrm{Li}_{4} \mathrm{Ti}_{5} \mathrm{O}_{12}$ anode material for enhancing the high rate performance. Electrochimica Acta 2013, 107: 139-146.

Open Access This article is licensed under a Creative Commons Attribution 4.0 International License, which permits use, sharing, adaptation, distribution and reproduction in any medium or format, as long as you give appropriate credit to the original author(s) and the source, provide a link to the Creative Commons licence, and indicate if changes were made.

The images or other third party material in this article are included in the article's Creative Commons licence, unless indicated otherwise in a credit line to the material. If material is not included in the article's Creative Commons licence and your intended use is not permitted by statutory regulation or exceeds the permitted use, you will need to obtain permission directly from the copyright holder.

To view a copy of this licence, visit http://creativecommons. org/licenses/by/4.0/. 